\title{
Herd Behavior and Market Stress: The Case of Four European Countries
}

\author{
Haroon Khan (Corresponding Author) \\ CERGAM, Institute d'Administration des Entreprises d'Aix-en-Provence (IAE) \\ Aix en Provence cedex 2, France \\ Tel: 33-(0)6-7385-1112Ｅ-mail: haroon.khan@iae-aix.com
}

Slim A. Hassairi

IMPGT, Aix en Provence

Jean-Laurent VIVIANI

CREM, Université de Rennes 1, Rennes, France

Received: January 10, 2011 Accepted: January 27, 2011 doi:10.5539/ibr.v4n3p53

\begin{abstract}
Despite the number of studies that have been carried out on the stock markets, quite a rare have in particular analyzed the tendency of herd behavior of countries in the European Union. Therefore, the emphasis is traditionally put on Asian countries and the United States. The detection of the herding phenomena is particularly made with subjective or extrapolative techniques. Consequently, our study is relevant on two levels since that, on one hand, it focuses on European countries and, on the other hand, it aims to verify the existence or non existence of the herding phenomena according to the method elaborated by (Hwang, S; Salmon, M (2000, 2004,2008).
\end{abstract}

Keywords: International capital markets, Herd behavior, Equity return dispersion, International finance

Classification JEL: G15, G31

\section{Introduction}

This study is focused on Herd behaviour and market stress using the models of, and that of. The data was collected from four European countries namely France, UK, Germany and Italy. It has been found that these countries' capital and securities market follow the herd behaviour in the events of crisis.

In the literature of behavioral finance, herd behaviour is often used to describe the correlation in the trades resulting from interactions between investors. This behavior is considered to be rational for less sophisticated investors, who try to imitate financial gurus or monitor the activities of successful investors, since the use of their own information and knowledge lead to greater cost. Villatoro (2009) investigates the association between financial intermediaries' (FI) reputation and herding and argued that financial intermediaries with high reputation are prone to invest in information, whereas those with poor reputation will tend to imitate other financial intermediaries' portfolio decisions. The consequence of this behavior is herd behaviour, Nofsinger and Sias as (1999) notes,"a negotiating group of investors in the same direction over a period of time. "Empirically, this can lead to observed behaviors that are correlated between individuals and causing systematically erroneous decision making by entire populations (Bikhchandani et al., 1992).

As for us, we retain the notion of herd behaviour as (Bikhchandani and Sharma 2000) for which "an individual is said to herd, if, without knowing the decisions of other investors, would have made the investment, but not undertake when it finds that other investors have decided not to undertake the investment. We therefore speak of herd behavior analysts and investors when they decide to ignore their own information and follow signs for observed decisions of other analysts and investors."

Other authors such as (Grinblatt, Titman and Wermers 1995), and (Nofsinger and Sias 1999) propose a broader definition of herd behaviour, as "having a group of investors transacting in the same way, in a same direction (buy or sell) for a given period of time. However, the correlation in investor behavior does to the extent that they influence each other. This correlation may be observed if investors are independently influenced by factors and / or common information. "

(Hirshleifer, D Teoh, SH 2003) distinguish between two types of behavior, "and they mean by" herd behaviour "(herd behavior) the convergence of behaviors and" informational cascades "situations where the individual's chosen action based on the observation of others regardless of his own informational signal. Thus, to achieve the same degree of diversification, investors need a larger selection of titles that are a lower degree of correlation. In addition, if market participants tend to flock the market consensus, the market behavior of investors may cause asset prices to deviate from economic fundamentals. Consequently, assets are not fairly priced. A number of studies have paid attention to market participants' herding behavior, ranging from mutual fund managers to institutional analysts. 
Such as, Grinblatt et al. (1995) found evidence of herding activity in mutual fund markets since fund managers tend to buy those securities that can make profit. Their confirmation pointed out that 77 percent of mutual fund investors are "momentum investors." Welch (2000) found that the latest revisions of investment recommendations influence positively the next analyst's revision. He suggested that herding toward the consensus is less likely to be caused by fundamental information, implying that analysts made their decision to herd on the basis of little or no information.

While Wermers (1999) found little herding by mutual fund managers in trading average stocks; more support of herding in trades of small securities and in trades by growth-oriented funds was found. Lakonishok et al. (1992) reported that pension fund managers trade the same stocks that other managers' trade and they follow a strategy of positive-feedback. On the contrary, some of the literature fails to detect herding behavior for certain market participants. In a research by Gleason et al. (2004), he found investors not herding during the periods of extreme movements in the market using ETFs. Also, it was found that the market's response to news is not symmetric for up markets and down markets.

Empirical studies of the herd behaviour behavior in the financial markets have pronged into two paths.

The first track focuses on the behavior of co-movement based on the measurement of dynamic correlations. For example, in their tests of financial contagion, Corsetti et al. (2005) found "some contagion, some interdependence' between the Asian stock markets. Chiang et al. (2007) reported that contagion occurred during the first phase of Asia financial crisis and the herd behaviour dominated the later stage

of the crisis, as the bad news became widespread and investors comprehended the shock of the crisis. Boyer et al. (2006) found that, in emerging stock markets, there is greater co-movement during high volatility periods, signifying that crises stretch through the holdings of international investors are mainly due to contagion rather than changes in fundamentals.

In another research of in a research of Cai et al. (2009) on the dynamic correlations among the six international stock Market indices (U.S., UK, France, Germany, Japan and Hong Kong) and their relationship with the volatility of inflation and the fluctuations in market. It was found that international equity correlations are significantly variable in time and their growth is linked to the cyclical fluctuations in rates of inflation rates and inventory volatility.

The second strand of studying the herd behaviour behavior focuses on scattering cross-sectional correlation of stock returns in response to the excessively changing market conditions. On investigating the information asymmetry in emerging markets, the researchers have predicted that investors in these markets are more probable to show herd behaviour. While studying international herd behavior, Chang et al. (2000) found considerable evidence of herd behaviour in South Korea and Taiwan and partial data from herd behaviour in Japan. However, there is no evidence of herd behaviour on the part of market participants United States and Hong Kong. By focusing on stocks in Hong Kong, Zhou and Lai (2009) found that herd behaviour activity in the market of Hong Kong tends to be more frequent with the shares of small investors are more likely to herd when selling rather than buying stocks. Turing to the Chinese, Demirer and Kutan (2006) study if investors in Chinese markets, making their investment decisions, are below the market consensus rather than private information during periods of market stress. Their study reveals no evidence of herd behaviour training, suggesting that the market Participants on the Chinese stock markets to make investment choices rational. Yet in a recent study of Chinese stock markets, Tan et al. (2008) report that herd behaviour occurs under rising and falling market conditions and is especially present in Investor A shares. Hwang and Salmon (2006) observe herding behavior in the markets of US, the UK, and the South Korean stock markets, and they find beta herding when investors believe they know where the market is heading rather than when the market is in crisis.

Thus, the evidence from the studies cited above shows diverse results and that most of the herding behavior is present in emerging markets and not on the leading markets. Although the above studies have contributed to describe the herd behaviour in various markets overall, they are mainly confined to the limits of a single market. No attempts were made to examine the herd behaviour across borders especially in Europe. The empirical results based on this framework are capable of producing two drawbacks. This article differs from previous research on the following points. First, the data set used by Chang et al. (2000), Demirer and Kutan (2006), Tan et al. (2008), and Zhou and Lai (2009) in their investigation of herd behavior is limited to asian and US markets. This study includes Four European countries data. Specifically, we find evidence of herding behavior occurring in countries classified as high-tech markets and European markets. In the following lines the research will be explained in detail. In first section we give the details about the concepts of herd behaviour and later on discuss the models used with the analysis of the results discussed later on.

\section{Multi-Factorial Model Used}

In this section, we will discuss initially the sophisticated models (Hwang S, Salmon M 2001) (Hwang, S; Salmon, M 2004) and (Hwang S, Salmon M 2008). We present thereafter in a second part this model as a basis for our study. 


\subsection{Model of Hwang and Salmon (2001, 2004, 2008)}

The (Hwang S, Salmon M 2001) and (Hwang S, Salmon M 2004) had observed the investment behavior of agents in the U.S. stock market. They are based on a new more powerful approach that uses a more comprehensive model including several factors that explain security returns (i,e the market portfolio named "beta herding" in their works (Hwang S, Salmon M 2008)), size and value. Using cross-sectional dispersion of the sensitivities of stocks to these factors offers a potential measure of herding in relation to other factors and control "to change the fundamentals." The estimated coefficients on the various factors were made through a multi - factorial (APT).

In their research (Hwang S, Salmon M 2008) used a sample with data on countries of United States, United Kingdom and South Korea. The data was monthly and came from (Center for Research in Security Prices $(C R S P))$ to measure the herding in the U.S. stock market. This includes securities listed on the NYSE, (NYSE) American Stock Exchange (AMEX) and NASDAQ. Their sample was comprised of 488 monthly observations from July 1963 to December 2003. The excess return is the market value weighted return of all shares of NYSE, $A M E X$ and NASDAQ and the less the rate of return on U.S. Treasury Bond to a month is also used. For other factors (Fama, EF, French, KR 1993), they use the size (Small Minus Big SMB), Book to market (High Minus Low $H M L$ ), and momentum data extracted from Kenneth and French. (Note 1)

Regarding the study that was conducted previously by (Hwang, S; Salmon, M 2001), they use the security indices fences of three countries, which are FTSE350 for the United Kingdom, S\&P500 for the United States and KOPSI 200 for South Korea. (Hwang S, Salmon M 2001) found herding important due to the Asian crisis and Russian (in years 97 and 98).

They also notice that, during under period of the crisis, there was a certain retreat of the herding whereas the market was in strong fluctuation. Moreover, they note that the tagging along related to the factor size is much more important than the other factors of the value and the growth. However, the factor value reflects a much greater herding than others during crises. It should be noted, however, that the empirical results, relating to the developed markets, tend to indicate that the investors show certain herding. In emerging markets, this trend appears more clearly.

Nevertheless, the results of these studies remain incomplete. They believe that the standard deviation, cross-sectional returns of individual stocks, is not independent of the volatility time series, as noted by (Christie and Huang 1995). But instead, according to (Hwang and Satchel 2002) and (Goyal and Santa-Clara 2003), they are theoretically and empirically correlated significantly positive. Therefore, even if there is a negative relationship between the standard deviation in cross section and the dummies (dummy) that does not mean that it comes from a change in volatility or a Herd Behaviour.

Besides this problem, it is noteworthy that the tension of a market does not necessarily mean that the overall market should record movements of extreme performance. Thus consider that the herding is manifested in the presence of extreme market movements can be misleading. Moreover, the absence of control mechanisms of the various movements in fundamentals makes detection difficult herding. Therefore, we cannot distinguish whether we are witnessing a recovery more or less efficiently by the market. This is why it is sensible and appropriate to adopt a new model that incorporates several variables. This was attempted to do (Hwang S, Salmon M 2001) (Hwang, S; Salmon, M 2004) and (Hwang S, Salmon M 2008). We intend to present it in what follows.

\subsection{Multivariate model}

The model for asset pricing CAPM in equilibrium is defined as follows:

$$
E_{t}\left(r_{i t}\right)=\beta_{m i t} E_{t}\left(r_{m t}\right)
$$

with $r_{i t}$ and et $r_{m t}$ representing the excess return of assets ' $i$ ' and the market at the moment ' $t$ ', $\beta_{m i t}$ is a measure of systematic risk and $E_{t}\left(r_{i t}\right)$ is conditional probability at the moment. Note that this model is not without drawbacks. First, it is conjectured that the herding is manifested by a decrease in cross-sectional dispersion coefficients on the performance of the market portfolio. For example, when investors are opting for strategies herding the market trend, the scattering cross section $\beta_{\text {mit }}$ would be the lowest compared to the situation where there is no follower.

When speculators are unaware of their own decisions in favor of the market, more than they would in equilibrium, this has the main consequence of aligning individual returns around the market return. Thus, the bias $\beta$ will be $(\beta>1$ the biased downward and vice versa). It should be noted however that this behavior is more likely during periods of crisis and when the market return increases or decreases sharply. It is anticipated that the dispersions $\beta$ decrease significantly during these periods.

In addition, the classic CAPM does not predict changes in the relationship between individual returns and market returns during crises. This method is not primarily dependent on changes in the relationship between the performance of individual stocks and market returns is not the time series volatility of market returns. 
In addition, this model advocates that $\beta_{\text {mit }}$ do not vary with time, however (Harvey 1989) and (Ferson, WE, Korajczyk, RA 1995) demonstrates otherwise. Moreover, this variation through time is due to debt firms. For example, according to (Black, F 1976) and (A. Christie 1982), if a firm chooses to change its capital structure and heavily into debt, there will be a slight change in $E_{t}\left(r_{m t}\right)$ which will result in a greater variation essentially $E_{t}\left(r_{i t}\right)$. Thus, $\beta_{\text {mit }}$ should increase. Moreover, it is noteworthy that when the firm changes its business, there may be a variation. All of these variations, for the reasons just mentioned, are termed rare in reality. It is unlikely to occur in a limited time interval. From (E. Ghysels 1998), it is difficult to use models of $\beta$ with varying over time and not having a model capable of detecting all the different variations, knowing that vary slightly. It considers the use of the assumption of $\beta$ constant through time for the valuation of financial assets is the best solution. Finally, (Cho and Engle 1999) find that $\beta$ increases if they are in the presence of bad news and vice versa.

Based on the results already mentioned, we can explain the benefits of adopting this new approach is more powerful to detect the herding, and especially that little distinction between "intentional herding" and "herding spurious" .

On the one hand, good (or bad) news firms should be low compared to the dispersion in cross-over variances and average cross-sectional $\beta$ expected to remain unchanged as the reaction to the new medium becomes negligible. On the other hand, as good (or bad) news of the market are common to all leaders, we can expect changes in $\beta$ individual or to an increase or a decrease (in case of bad news) without changing the scattering cross section. Accordingly, and in reference to the hypotheses of CAPM, it can be a divergence of individual returns without the dispersion $\beta$ changes. Thus we can use variations of the dispersion coefficients on the performance of the market portfolio for the detection of herding behaviour in the financial markets.

\subsection{Modeling}

While the model (Chang, Cheng and Khorana 2000) implies the existence of herding that is either true or false without trying to explain, the multivariate model focuses on the microeconomic aspect of the phenomenon. These models allow the hypothesis that $r_{i t}$ is simply the excess return of security $i$ at time $t$. The multivariate linear model, when we turn, is defined as follows:

$$
r_{i t}=\alpha_{i t}+\beta_{m i t} r_{m t}+\sum_{k=1}^{K} \beta_{k i t} f_{k t}+\varepsilon_{i t}
$$

Where $i=1, \ldots \ldots, N$ and $t=1, \ldots \ldots, T$ and $\alpha_{i t}$ represents a constant that varies with time, $\beta_{\text {mit }}$ is the coefficient on the excess return of market portfolio and $\beta_{k i t}$ is the coefficient on the $\mathrm{K}$ factor at time $t . \quad r_{m t}$ and $f_{k t}$ represent the excess return of market portfolio and the realized value of K-factor at time $t$.

The cross-sectional probability which is essential for measuring the herding is defined as:

$$
E_{c}\left(x_{t}\right)=\sum_{i=1}^{N} w_{i t} x_{i t}
$$

$w_{i t}$ with weight equal to the investment market in asset $\mathrm{i}, \mathrm{N}$ is the number of assets on the market. This weighting is a probability measure since $w_{i t} \geq 0$ for all $i$ and $t$ and $\quad \sum_{i=1}^{N} w_{i t}=1$ for all values of $t$.

Hence, we can calculate the averages and variances in cross-section of asset returns at time $t$.

$$
\begin{gathered}
r_{m t}=E_{c}\left[r_{i t}\right] \\
=E_{c}\left[\alpha_{i t}+\beta_{m i t} r_{m t}+\sum_{k=1}^{K} \beta_{k i t} f_{k t}+\varepsilon_{i t}\right] \\
=E_{c}\left[\alpha_{i t}\right]+r_{m t} E_{c}\left[\beta_{m i t}\right]+\sum_{k=1}^{K} f_{k t} E_{c}\left[\beta_{k i t}\right]+E_{c}\left[\varepsilon_{i t}\right]
\end{gathered}
$$

Concerning the Equation (2) and taking into account the assumption of no correlation between different factors, we have:

$$
\begin{aligned}
& E_{c}\left[\beta_{m i t}\right]=1 \\
& E_{c}\left[\beta_{k i t}\right]=0, \forall k \\
& E_{c}\left[\varepsilon_{i t}\right]=0
\end{aligned}
$$

$$
E_{c}\left[\alpha_{i t}\right]=0
$$

However, this measure may be biased by the use of market weight in the title in question to securities with higher market capitalizations. Thus, we consider in what follows that all the weights are distributed equally to the calculation of the variance in cross section as we are concerned with changes in $\beta$.

With $\overline{\hat{\beta}}_{m i t}=\frac{1}{N_{t}} \sum_{i=1}^{N_{t}} \hat{\beta}_{m i t}$, and $N_{t}$ is the number of stocks.

$$
v \hat{a} r_{c}\left(\hat{\beta}_{m i t}\right)=\frac{\sum_{i=1}^{N_{t}}\left(\widehat{\beta}_{m i t}-\overline{\hat{\beta}}_{m i t}\right)^{2}}{N_{t}}
$$

$$
v \hat{a} r_{c}\left(\hat{\beta}_{k i t}\right)=\frac{\sum_{i=1}^{N_{t}}\left(\widehat{\beta}_{k i t}-\overline{\bar{\beta}}_{k i t}\right)^{2}}{N_{t}}
$$

With $\quad \overline{\hat{\beta}}_{k i t}=\frac{1}{N_{t}} \sum_{i=1}^{N_{t}} \hat{\beta}_{k i t}$

Note that the herding from the portfolio is defined as a reduction will $v \hat{a} r_{c}\left(\hat{\beta}_{\text {mit }}\right)$ while the herding on the $K$ factor is defined as being increase in $v \hat{a} r_{c}\left(\hat{\beta}_{k i t}\right)$. When will $v \hat{a} r_{c}\left(\hat{\beta}_{m i t}\right)$ increases this means that many individual $\beta$ becomes significantly different, reflecting the fact that increased $\beta>1$ is a lower $\beta<1$. In other words, this means that the returns of individual stocks are more scattered around the market return and consequently less herding 
behaviour. In contrast, a rapid and significant decrease of going $v \hat{a} r_{c}\left(\hat{\beta}_{m i t}\right)$ shows a gathering of systematic risk around 1 , which is manifested by more adjustment in the valuation of assets relative to market performance, is a behavioral herding relative to market returns. On the other hand, when $v \hat{a} r_{c}\left(\hat{\beta}_{k i t}\right)$ increases, some $\beta$ deviate significantly from expected since the average cross-sectional coefficients on other factors is always zero. Any 0 gap of $\beta$ coefficients indicates the presence of herding around the factor at time $t$ is reflected by a large value of the scattering cross section i,e $v \hat{a} r_{c}\left(\hat{\beta}_{k i t}\right)$. These definitions are in no way be construed as exhaustive and exclusive measure of the phenomenon of herding. However, they can see the herding through time and compare herd behavior between different markets, sectors or groups of securities between individuals. This is the aim of detecting the existence of herd behavior in the security markets of countries joining the European Union.

On this measure, we must emphasize that it requires an estimation of the model (2) by the method of least squares $(O L S)$. As for the estimate of $\beta$ different variations over time, this implies according to (Ferson, WE and Harvey, CR 1995), additional information. Hence it is assumed that $\beta$ is constant over a certain time interval $\tau$ and noted that the systematic risks vary slightly over time. Also, be aware that when $\tau$ is large, changes in $\beta$ will not be well captured and the reverse is true if $\tau$ is small, it makes the OLS estimators inefficient. Generally, when we deal with monthly observations, we use 5 and 7 for $\tau$ years. Using $\tau$, we can write:

Where $r_{i, t}=\left(r_{i, t-\tau+1} r_{i, t-\tau+2} \cdot r_{i, t}\right)^{\prime}, \boldsymbol{X}_{t}=\left(\begin{array}{ccccc}1 & r_{m, t-\tau+1} & f_{1 t-\tau+1} & \cdot & f_{K t-\tau+1} \\ 1 & r_{m, t-\tau+2} & f_{1 t-\tau+2} & \cdot & f_{K t-\tau+2} \\ \cdot & \cdot & \cdot & \cdot & \cdot \\ 1 & r_{m, t} & f_{1 t} & \cdot & f_{K t}\end{array}\right)$

$$
\begin{gathered}
\beta_{i t}=\left(\alpha_{i t} \beta_{i m t} \beta_{i l t} \cdot \beta_{i k t}\right)^{\prime} \text {, and } \varepsilon_{i t}=\left(\varepsilon_{i t-\tau+1} \varepsilon_{i t-\tau+2} \cdot \varepsilon_{i t}\right)^{\prime} \text { OLS estimators for security } i \text { at time } t \text { are } \\
b_{i t}=\left(X_{t}^{\prime} X_{t}\right)^{-1} X_{t}^{\prime} r_{i t}, \quad \operatorname{var}\left(b_{i t}\right)=\sigma_{i}^{2}\left(X_{t}^{\prime} X_{t}\right)^{-1}
\end{gathered}
$$

Where $\sigma_{i}^{2}=E\left(\sigma_{i t}^{2}\right)$ that can be estimated with $s_{i}^{2}=\frac{1}{\tau-K-2} \sum \sigma_{i t}^{2}$ and $\sigma_{i t}$ is the residual of the OLS regression. $S^{m}$ (or $\left.S^{K}\right)$ is the diagonal $\left(X_{t}^{\prime} X_{t}\right)^{-1}$ for the market factor (or factor $K$ ).

The major drawback of OLS estimators is that some estimates $\beta_{\text {mit }}$ or the $\beta_{k i t}$ (respectively $\hat{\beta}_{\text {mit }}$ and $\widehat{\beta}_{k i t}$ ) are not significant and very remote to 0 or 1 . Consequently, they may have important effects on the dispersion in cross section of $\hat{\beta}_{m i t}$ or $\hat{\beta}_{k i t}$. In this way, we could wrongly conclude that there is no herding around $R_{m}$, conversely we are in the presence of herding behaviour and the relation to one specific factors. To circumvent these problems (Hwang, S; Salmon, M 2001) and (Hwang S, Salmon M 2004) continued to a division of $\hat{\beta}_{m i t}$ and $\hat{\beta}_{k i t}$ of the sample standard deviation in their own time series. The extent of herding around the market portfolio is defined as follows:

$$
H(m, t)=\operatorname{var}_{c}\left(\frac{\widehat{\beta}_{m i t}-1}{\sqrt{s_{i}^{2} s^{m}}}\right)
$$

if the measure of extent of herding is around factor $\mathrm{k}$, it will become:

$$
H(k, t)=\operatorname{var}_{c}\left(\frac{\widehat{\beta}_{k i t}}{\sqrt{s_{i}^{2} s^{k}}}\right)
$$

Where $\hat{\beta}_{\text {mit }}$ and $\hat{\beta}_{k i t}$ are OLS estimators of model (2) respectively on the market portfolio and the factor $\mathrm{k}$ for security $i$ at time $t$ and $s_{i}^{2}=\frac{1}{\tau-K-2} \sum e_{i t}^{2}$ where $e_{i t}^{2}$ with the residuals from the regression, $S^{m}$ (respectively $S^{k}$ ) is the diagonal matrix $\left(X_{t}^{\prime} X_{t}\right)^{-1}$ corresponding to the market factor and yields on $\mathrm{K}$ factors between $t-\tau+1$ and .

These measures are derived from the cross-sectional variance of t-statistics of OLS estimators on market performance and the factors K(Hwang S, Salmon M 2001) show that when $N_{t}$ is high enough:

$$
H(m, t)=\frac{1}{N} \sum_{i=1}^{N_{t}} \frac{\left(\hat{\beta}_{m i t}-1\right)^{2}}{\sqrt{s_{i}^{2} s^{m}}} \sim \chi^{2}\left(N ; \hat{\delta}_{m}-N\right)
$$

$H(k, t)=\frac{1}{N} \sum_{i=1}^{N_{t}} \frac{\left(\widehat{\beta}_{k i t}\right)^{2}}{s_{i}^{2} s^{k}} \sim \chi^{2}\left(N ; \hat{\delta}_{k}-N\right)$

with $\hat{\delta}_{m}=\sum_{i=1}^{N_{t}} \frac{\left(\hat{\beta}_{m i t}-1\right)^{2}}{\sigma_{i}^{2} s^{m}}$ and $\hat{\delta}_{k}=\sum_{i=1}^{N_{t}} \frac{\left(\hat{\beta}_{k i t}\right)^{2}}{\sigma_{i}^{2} s^{k}}$ that represent the parameters of non-centrality of the chi square distribution. Based on this method, we identified a significant level of herding that either an increase or decrease over time. For each time $\mathrm{t}$, and for each measurement of $H(m, t)$ and $H(k, t)$ as defined by equations (11) and (12), we have at our disposal confidence intervals defined by the Equation (13). Thus, we can use the confidence interval calculated at time $\mathrm{t}$ to test if the measure of herding records change significantly between $t$ and $t+1$. Under 
the assumption of the CAPM equilibrium, we can not foresee significant changes in $H(m, t)$ between $t$ and $t+1$ for each time t. A significant decrease of $H(m, t)$ shows the presence of a herd behavior relative to market returns.

It is important to establish a baseline of herding against which we detect any deviations. This will allow us to measure the herding against this benchmark. It should be noted, moreover, that this reference requires an estimation of the model. Thus, given that the benchmark is subjective, we can consider the average or the median measure of herd behavior as a benchmark to remember. Finally, it should be noted that through this measure we can compare the phenomenon of herding between different markets, sectors or groups of securities. For this, we must compare the average (or median) (eg, groups of stocks) of the measure $H(m, t)$. If the latter measure is less than the average indicates more than herding; by cons for herding around other factors, a measure $H(k, t)$ indicates an average of less pronounced herding less about this factor.

According to (Avery and Zernsky 1998), the herding is the consequence of asymmetric information between market makers and investors informed. On the other hand, the different structures of the stock markets have different levels of information availability and transparency. Auction markets, for instance differ in sensitivity to their lesser articulate asymmetric information markets counterpart. To study the effect of market structure on the herd behavior of players, we compare measurements of herding between some countries in the European Union.

2.4 Conclusion

We conduct a comparison of dual-herd behavior in different markets. First, the scattering cross section of $\beta$ markets is presumed as an indicator of the consolidation of asset valuations around the aggregate performance of the market. Since, herd behaviour is relative, so a measure $H(m, q)$ relatively low average on a stock market shows that there is more than average herding around the aggregate yield on the stock exchange. For cons, the follower way compared to other factors leads to a greater extent on average of $H(k, t)$ since a deviation of $H(m, t)$ indicates the use of remote factor $k$ in investment strategies by speculators and by taking joint actions with regard to these factors. Second, the impact of herd behavior on asset prices and sudden and significant decreases of $H(m, t)$ indicate that the herd behavior affects the efficient recovery of assets, especially in times of crisis. A modification beyond the confidence intervals of $H(m, t)$ between $t$ and $t+1$ indicates an increased presence of herd behavior.

\section{Application of Model of Hwang and Salmon}

\subsection{Analysis}

\subsubsection{Introduction}

In this part of article, we will discuss the linear model proposed by three factors (Fama, EF, French, KR 1993) that corrects the shortcomings of the pricing model of financial assets. (Note 2) This model includes the market risk (beta used in the CAPM), and also uses the risk associated with size and the factor related to the ratio (Book to market) which is none other than the book value over market value of the security. In order to better explain the variability of returns of companies(Note 3) the equation of the model to three factors (Fama, EF, French, KR 1993) is as follows:

$$
r_{i, t}=\alpha_{i, t}+\beta_{i, m t} r_{m, t}+\beta_{i, S t} S M B_{t}+\beta_{i, H t} H M L_{t}+\varepsilon_{i, t} .
$$

where $r_{m, t}$ is the excess return of market portfolio, $r_{i, t}$ is the excess return of security $i, S M B_{t}$ (Small Minus Big), is the premium required by financial markets for small businesses and $H M L_{t}$ (High Minus Low), the premium required by financial markets for business value (not growing). The parameters $\alpha_{i, t}, \beta_{i, S t}, \beta_{i, H t}$ of this model are estimated by linear regression. The intercept $\alpha_{i, t}$ can detect abnormal return of a security, $i, e$ the portion of return that exceeds or is below the expected performance, given the excess risk of market and factors of size and ratio of $V C / V M$.

\subsection{Methodology}

The procedure selected in order to evaluate the parameters of this model is as follows: we use the first 60 observations going of March 1998 until February 2003 to obtain the estimators for each action, which then enables us to calculate the variance out of transverse section of the statistics $t$ for February 2003. Then, we add an observation at the end of the sample and we eliminate the first to obtain the 60 following observations and to thus calculate the statistics for March 2003, and so on.

The following table illustrates the methodology used by (Fama, EF, French, KR 1993). The $S M B$ (Note 4) factor is the average yield gap between small and large businesses. The $H M L$ (Note 5) factor represents the average yield spread between corporate value and growth companies.

The following table illustrates the methodology used by. The two strategies of investments are built as follows:

$$
\begin{gathered}
H M L_{t}=1 / 9 *\left(\left(P_{1}-P_{19}\right)+\left(P_{2}-P_{20}\right)+\left(P_{3}-P_{21}\right)+\left(P_{4}-P_{22}\right)+\left(P_{5}-P_{23}\right)+\left(P_{6}-P_{24}\right)+\left(P_{7}-P_{25}\right)+\left(P_{8}-P_{26}\right)+\left(P_{9}-P_{27}\right)\right) . \\
S M B_{t}=1 / 9 *\left(\left(P_{1}-P_{7}\right)+\left(P_{2}-P_{8}\right)+\left(P_{3}-P_{9}\right)+\left(P_{10}-P_{16}\right)+\left(P_{11}-P_{17}\right)+\left(P_{12}-P_{18}\right)+\left(P_{19}-P_{25}\right)+\left(P_{20}-P_{26}\right)+\left(P_{21}-P_{27}\right)\right) .
\end{gathered}
$$

Insert table 1

We report below the descriptive statistics of various factors. In Table 3 countries are reported in the first column, followed by the mean, standard deviation and Student $\boldsymbol{t}$ test. Factor SMB (Small minus Big) is the average yield gap 
between small and large businesses. The variable HML (High minus Low) is the average yield spread between corporate value and growth companies.

\section{Insert Table 2}

\section{Measuring the Herding Behaviour}

The first part of article we tried to analyze the behavior around the herd performance of the market. The second part focuses on the extent of herding around the two factors, namely size and Book-to-market.

4.1 Measure of herding around the market performance

We are proceeding in what follows to analyze the behavior herd around the market's performance in comparison with a double first by market and in a second time between the markets.

4.1.1 Measure of herding in the performance of the market.

We note that the entire sample, between 2007 and 2008, shows a large herding behaviour around the market portfolio. (Note 6) In all these cases, low values of $H(m, t)$ are recorded when the markets were heavily bullish. The trend towards low values of $H(m, t)$ can be detected early in our period of study in some countries such as Germany.

Although there are some fluctuations over time, both in the UK market, German and Italian, it shows a herding around the market return in times of intense market fluctuations. The smallest $H(m, t)$ is observed just after the global financial crisis (Dot com Bubble Burst): 2000-2002. After this last point, the estimated value of $H(m, t)$ became larger and the market portfolio does not seem to act as an attractor of attention of investors and therefore we confirm the presence of herding. For example, we believe that $\mathrm{H}(\mathrm{m}, \mathrm{t}$ ), after the international (subprime) (Note 7) financial crisis has almost doubled compared to that before the crisis for Germany and England between 2005 and 2006. Another proof of herding behaviour can be found on the French and Italian during the period of relatively normal fluctuation before the (subprime) crisis. The same figure shows that before the Dot com Bubble Burst in mid 2004, the statistics of herding behaviour were significantly lower after the crisis. Once again, our statistical herding has more than doubled from there to the end of 2005. Therefore, after the crisis, the tendency towards conformism around the market portfolio has dropped considerably.

Presumably, the most striking fact that emerges from our measure of herding is that the whole financial market is characterized by the existence of significant peaks. In addition, the decay of the largest and most significant of $H(\mathrm{~m}$, t) took place between 2005, 2006 and late 2007 for all countries, indicating a Herd Behaviour in these two important dates. In fact, $H(m, t)$ increased from 19 to 12 for France, from 25 to 10 for Germany, 16 to 11 for Italy and to 4.8 for England.

Then a second sudden change occurred between 2007 and 2008, where $H(m, t)$ increased from less than to France, for 10 to Germany and Italy for 12 and under and to (during the same period, there was a twofold increase followed by decrease) in England. These declines are significant since they are below average. These two significant decreases in $\mathrm{H}(\mathrm{m}, \mathrm{t})$, which show a marked herd behavior around the performance of the market portfolio, coincide with the bursting after the Internet bubble, which affected the "tech stocks", $\mathrm{c}$ that is to say those sectors related to computing and telecommunications, the stock market in the late 1990s. Its peak occurred in March 2000, and his fall was spread over two years ie from 2001 until 2002 with the start of the (subprime) crisis is a financial crisis and global market, triggered in 2006 by a bust of (subprime) mortgages in the United States. The housing crisis began to have a real impact in February 2007 that turned into a real global crisis in the summer of 2007. We proceed in what follows a comparison of the extent of herding around the performance of the market for all countries.

Insert Fig 1 \& 2

4.1.2 Comparison of the extent of herding between all markets

In the following figure, or the extent of herding around the performance of the contract is delayed to allow us to compare levels of herding behaviour among different markets. If we compare periods of normal fluctuation of the market share in France, Italy, Germany and England, the statistical herding these markets are generally between 11 and 10 and between 2.11 and between and between and 2.6. This means that the UK market shows less herding behaviour around the market portfolio than other markets. The average estimated values of statistics of herding for the 4 countries are about 12,11, 10, and 5.2 respectively. Note that there is a similar trend between French and Italian markets.

Our results seem consistent with those of (Hwang S, Salmon M 2001) (Hwang, S; Salmon, M 2004) and (Hwang S, Salmon M 2008), which are able to validate the presence of herding in developed countries. These results confirm the presence of this phenomenon studied in the previous chapter.

Overall trends herds remain within each country. Trends are evidence of the testing of herding (Chang, Cheng and Khorana 2000) and (Christie and Huang 1995) during the period, 02/03/1998 to 29/02/2008, indicating therefore the existence of a herding in European countries. Our results do not seem inconsistent with previous work. Note that several studies conducted in developed markets are such that a partial presence (Bikhchandani and Sharma 2000) 
and unlike those in (Chang, Cheng and Khorana 2000) who manage to find evidence of this behavior in emerging markets such as Korea, but fail to detect such events in the U.S. market, as Hong Kong and Japan.

However, our results are not consistent with the idea that herding occurs only during periods of market turbulence (crises). Instead, we can relax this behavior even during periods of normal change course as it is reported in the graphs. An explanation is advanced by (Hwang S, Salmon M 2001) and (Hwang S, Salmon M 2004): when the market recorded periods of market turbulence, there may be other factors that replace the role of market portfolio and serve as an engine for herd behavior.

Another explanation states that herding occurs only when financial markets are under stress, and can be simply wrong. We can observe significant negative returns and positive returns for the majority of individual assets. We tend to conclude that the presence of herding behaviour in the overall market. However, the dispersion of returns is likely to be greater during periods of market turmoil than during otherwise.

Note that a lot of work attached to the concentration yields of the various actions around the market return during periods of strong price movements. This approach is based on the idea that in times of market turbulence or crisis, the different values tend to cluster more closely around the market, so that markets adopt a strategy of lower differentiation between the actions. For example, (Christie and Huang 1995) based on daily returns of U.S. stocks to show, using their measure of dispersion, the dispersion around the market return is relatively higher during strong fluctuations.

According to (Hwang S, Salmon M 2008), these results can be interpreted as going against the principle of herding and, as noted by Richards (1999), the test developed by (Christie and Huang 1995) does not identify all forms of herd behavior.

Insert fig 3

\subsection{Measure around the herding of different factors}

As it was stressed in the previous section, one of the major advantages of using this new approach is that one can estimate the herding through other factors. In what follows, we will use the same methodology, namely the multifactor model to search for possible follow-through behavior contracts mentioned above using the value and size factors in the German, French, English and Italian.

4.2.1 Measuring around herding factors SMB and HML

The same methodology will be adopted throughout this sub section; we will try to detect the behavioral follow-through management style.

The literature on management styles relates mainly econometric studies that seek to specify the determinants of these styles(Note 8). It comes to explaining actual performance or portfolio composition from known data. These data were first financial variables such as recent developments in progress or the level of capitalization companies. Although there is large number of management styles(Note 9), we will limit our search to Like (Fama, EF, French, KR 1993) by measuring the position in relation to two factors namely the size and value (book to market). This results in the following graphic where we defer action SMB and HML for the country. Figure 10 shows that the measure around the market portfolio is smaller than reported in Figure 12. Examination of the chart (12) shows that the SMB and HML factors have played a role of herding goals. Indeed, we observed a decrease in dispersion of betas around these two factors at the beginning of the period until 2004 for Germany, France and Italy. The latter played an important role for the entire duration for France. We see a growth from 2004 until mid-2007 reflecting the presence of a herding followed by a significant drop from 7 to 3.8 again we observe a slight increase during the (subprime) crisis in the Summer 2007. The size factor does not appear to play a decisive role throughout the study period, however, we note that there was a significant decrease of herding just before the crisis (subprime) from 4.3 to 3.5 and a rebound in crises. We also note a significant decrease of herding just after the bursting of the Internet bubble which rose from 4.25 to reach 2.5 .

From 2004 until the end of the period, the herding in relation to size (SMB) appears to have played an important management strategy for Germany and Italy. For Germany, we recorded a significant increase in tail-between June 2005 and April 2006 increased by 5.6 to reach the 10.2 for SMB and 8 to 12.8 HML. For Italy, we recorded increases of herding in relation to the size factor especially between 2007 and 2008 certainly attributed to the (subprime) crisis, which increased from 5 to 7.8 , now with respect to the factor values reflecting a significant increase herding between 2004 and 2005 and a significant decrease was registered in early 2008, i,e just after the crisis, which increased from 7 to 5.3 .

For the UK, we observe that the herding in relation to factor $H M L$ the beginning of the period until 2005 has played an important role. It has reversed since leaving room to $S M B$ factor until the end of the period. On the internet after crisis, we recorded a decrease of herding from 2003 to 2004 for factor SMB and $H M L$ for 2003 until 2005 and an increase on its two factors towards the end of 2007 's is to say just after the crisis (subprime). These results are consistent with the work of (Hwang S, Salmon M 2008). Presumably, the most striking fact that emerges from the 
two measures of herding is that all financial markets are characterized by the existence of significant peaks. In addition, the decay of the largest and most significant of $H(m, t)$ took place between 2005 and 2006 and late 2007 for all countries, indicating a Herd Behaviour in these two important dates. In fact, $H(m, t)$ increased from 19 to 12 for France, from 25 to 10 for Germany, 16 to 11 for Italy and to 4.8 for England.

We report what is to follow the two measures of herding behaviour around the two factors to compare the level of herding in relation to all countries engaged in the study. It appears from these graphs that Germany has the least herding behaviour.

\section{Insert fig 4}

\subsection{Comparison of both measurement of Herd Behaviour around SMB and HML between all the market}

We report what is to follow the two measures of herding behaviour around both size and value factors to compare the level of herding and see the differences in investment strategy due to the fact of differences in structures and modes of operation of different markets knowing that the securities listed on the 4 markets are not similar and of diverse characteristics. It appears from these graphs that Germany has the most herding behaviour compared to other countries with regard to herding around the size factor, followed by Italy and France who have a tendency quite similar. In UK, it is interesting to note that investors do not rely on this basic factor in their investment strategy.

Compared to the HML factor, we find that the level of herding behaviour from the book to market in France and England is the highest, followed by Italy and Germany, which finally shows the level of herding highest around the value factor. Remember however that despite these findings, they remain much lower compared to the size factor and even less about the market factor. Investment strategies focus and give more importance to the market factor than the two others and this is more prominent during the financial turmoil. We also observed from the figure above that its measures are far below market returns, implying that the market factor is correlated with other factors. When we consider two other factors, investors seem to be a Herd Behaviour based more on the market portfolio. When there are relatively more about herding between market performance (07/01/2007 and $1 / 12$ / 2008), other factors seem to play the role of herding behaviour as a goal. It is during this period, the measures of herding behaviour other factors showed no significant change. However, during the crisis (subprime), the market portfolio does not play a central role, investors have relied a bit more about the size factor for almost all countries. The measurement of herding behaviour around the value is very similar as far around the waist during the (subprime) crisis. However, during the crisis, estimated statistics about the size factor increased from 6 to 7.3 for example France. One explanation advanced by (Hwang and Satchel 2002) is that in a crisis, investors are averse to risk and become "risk averse" and providing, but just after they attach more importance to the factor that size factor market and, therefore, there is a preference for companies whose stock prices underestimate the fundamental value, we expect a significant increase in the companies whose activity is recognized and whose earnings growth is steady.

Given the results, the most striking feature of this study is that through the various steps of herding on the three factors, the herding around the market return is more common and more common for the countries studied during periods of normal fluctuation that situation in turbulence. However, when the market is in stress, more exactly in the (subprime) financial crisis, we see more of herding in relation to the size factor. Factor value does not appear to play an important role although throughout the period it is higher than the size factor.

Insert fig $5 \& 6$ here

It was subsequently noted that there were more than herding around the HML factor before the 1998 crisis. Moreover, there seems to be no relationship between herding over SMB and HML from around the herding of the market and market performance. Indeed, the correlation coefficients between the three measures of herding do not exceed 0.5 , and coefficients of correlation between measures of herding and performance of the market are low and are not significant.

\section{Conclusion}

This empirical study has attempted to explain the herding according to several factors namely market performance, size and book to market on European stock markets i,e French, German, Italian and English. Overall, this empirical illustration showed that by and large, there is a presence of herding behaviour in all countries, excluding periods of market turmoil and crisis.

Thus, it seems to validate many of the lessons of behavioral models, particularly that of Hwang and Salmon (2001, 2004, 2008).Specifically, the presence of herding around the market performance is the most common for the countries studied. The presence of this behavior in developed countries during periods of normal fluctuation is a major contribution.

However, the proposed (Chang, Cheng and Khorana 2000), which is based on the idea that in times of market turmoil and crisis, the different values tend to cluster more closely around the market, is not clearly verified. In fact, herding may occur, as expected, even in periods of normal fluctuation. 
Moreover, this study has focused entirely on four stock markets. We couldn't focus on all of the member countries of the European Union because of insufficient data, although the inclusion of these countries can contribute to a better understanding of the phenomenon. Also, this chapter does not take into account the momentum effect, that it is limited to 3 factors as (Carhart, 1997), the excess return of a portfolio of securities would be based on its sensitivity to 4 risk factors. The 3 factors (Fama, EF, French, KR 1993) are performance, size and value and a factor related to the momentum effect. It would be interesting to incorporate this effect in the econometric formulation to study the behavior of investment aggregating agents in the markets.

Finally, remember that the sample considered here spans the period from 2003 to 2008, a period characterized by two important events: the dotcom bubble and beginning of the crisis (subprime). In fact, for a better understanding of the phenomenon of herding, it is desirable to consider the two crises from beginning to end and incorporate the effects of this crisis (subprime) which at this writing these last sentences received much ink. The future work will be included in this perspective.

\section{References}

AAron, C., Bilon, I., Galanti, S., \& Tadjeddine, y. (2005). Les styles de gestion de portefeuille existent-ils? Working paper.

Avery, C., \& Zernsky, P. (1998). Multidimensional Uncertainty and Herd Behavior in Financial Markets. American Economic Review, 88, 724-748.

Bikhchandani, S., \& Sharma, S. (2000). Herd Behavior in Financial Markets: A Review. IMF Working Paper $W P / 00 / 48$.

Black, F. (1976). Studies of Sock Market Volatility Changes. Proceedings of the American Statistical Association, Business and Economics Statistics, 177-181.

Chang, E., Cheng, J. W., \& Khorana, A. (2000). An examination of herd behavior in equity markets: An international perspective. Journal of Banking \& Finance, 24.

Cho, Y., \& Engle, R. F. (1999). Time-Varying Betas and Asymmetric Effects of News:Empirical Analysis of Blue Chip Stocks.” NBER Working Paper Series 7330 (1999). NBER Working Paper(7330 ).

Christie, A. (1982). The Stochastic Behaviour of Common SecurityVariance: Value, Leverage and Interest Rate Effects. Journal of Financial Economics(10), 407-432.

Christie, W. G., \& Huang, R. D. (1995, Juillet-Août). Following the Pied Piper: Do Individual Returns Herd Around the Market? . Financial Analysts Journal, 31-37.

Fama, E F; French, K R. (1993). Common risk factors in the returns on stocks and bonds. Journal of Financial Economics, 33 (1), 3-56.

Ferson, W E; Harvey, C R. (1995). Predictability and Time-Varying Risk in World Equity Markets. Research in Finance(13), 25-88.

Ferson, W E; Korajczyk, R A. (1995). Do arbitrage pricing models explain the preclictability of securityreturns? Journal of Business(68), 309-349.

Ghysels, E. (1998). On Stable Factor Structures in the Pricing of Risk: Do Time $\neg$ Varying Betas Help or Hurt? Journal of Finance(53), 549-573.

Goyal, A., \& Santa-Clara, P. (2003). Idiosyncratic Risk Matters! Journal of Finance, 58, 975-1007.

Harvey, C. R. (1989). Time-varying Conditional Covariances in Tests of Asset Pricing Models. Journal of Financial Economics(24), 289-317.

Hwang, S., \& Satchel, S. E. (2002). Properties of Cross-sectional Volatility. Financial Econometrics Research Centre(WP00-4).

Hwang, S; Salmon, M. (2001, March). A New Measure of Herding and Empirical Evidence. (C. U. School, Éd.) CUBS Financial Econometrics Working Paper No WP01-3.

Hwang, S; Salmon, M. (2004). Market stress and herding. Journal of Empirical Finance, 11, 585-616.

Hwang, S; Salmon, M. (2008, February). Sentiment and Beta Herding. Working paper.

Notes

Note 1. http://mba.tuck.dartmouth.edu/pages/faculty/ken.french/data_library.html.

Note 2. CAPM

Note 3. Ratio VC / VM

Note 4. Small minus Big.

Note 5. High minus Low.

Note 6. Plz see Fig "Measure of Herding around the performance of Market".

Note 7. The crisis of the subprimes is a financial and stock exchange crisis in the world, started in 2006 by a crash of the loans

Note 8. Plz see Annex 1 "Different styles of Management". 
Note 9. Indicial, Quantitative, Sectoral, Strategic, growth and value

Table 1 : Procedure of Portfolio construction according to the model with three factors of Fama and French (1992, 1993)

\begin{tabular}{|c|c|c|}
\hline Book-to-market & Market capitalization & Portfolio \\
\hline \multirow[t]{9}{*}{ High } & Small & $P_{1}$ \\
\hline & & $\mathrm{P}_{2}$ \\
\hline & & $\mathrm{P}_{3}$ \\
\hline & Medium & $\mathrm{P}_{4}$ \\
\hline & & $\mathrm{P}_{5}$ \\
\hline & & $\mathrm{P}_{6}$ \\
\hline & Big & $\mathrm{P}_{7}$ \\
\hline & & $\mathrm{P}_{8}$ \\
\hline & & $\mathrm{P}_{9}$ \\
\hline \multirow[t]{9}{*}{ Medium } & Small & $\mathrm{P}_{10}$ \\
\hline & & $P_{11}$ \\
\hline & & $P_{12}$ \\
\hline & Medium & $\mathrm{P}_{13}$ \\
\hline & & $\mathrm{P}_{14}$ \\
\hline & & $P_{15}$ \\
\hline & Big & $P_{16}$ \\
\hline & & $P_{17}$ \\
\hline & & $P_{18}$ \\
\hline \multirow[t]{9}{*}{ Low } & Small & $\mathrm{P}_{19}$ \\
\hline & & $\mathrm{P}_{20}$ \\
\hline & & $P_{21}$ \\
\hline & Medium & $P_{22}$ \\
\hline & & $P_{23}$ \\
\hline & & $\mathrm{P}_{24}$ \\
\hline & Big & $\mathrm{P}_{25}$ \\
\hline & & $\mathrm{P}_{26}$ \\
\hline & & $P_{27}$ \\
\hline
\end{tabular}

Table 2 : Descriptive statistics of the factors

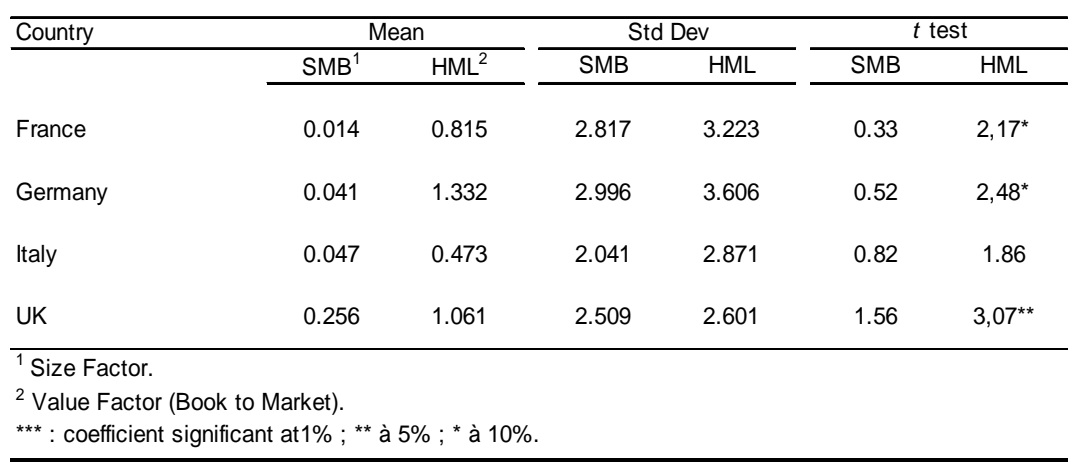



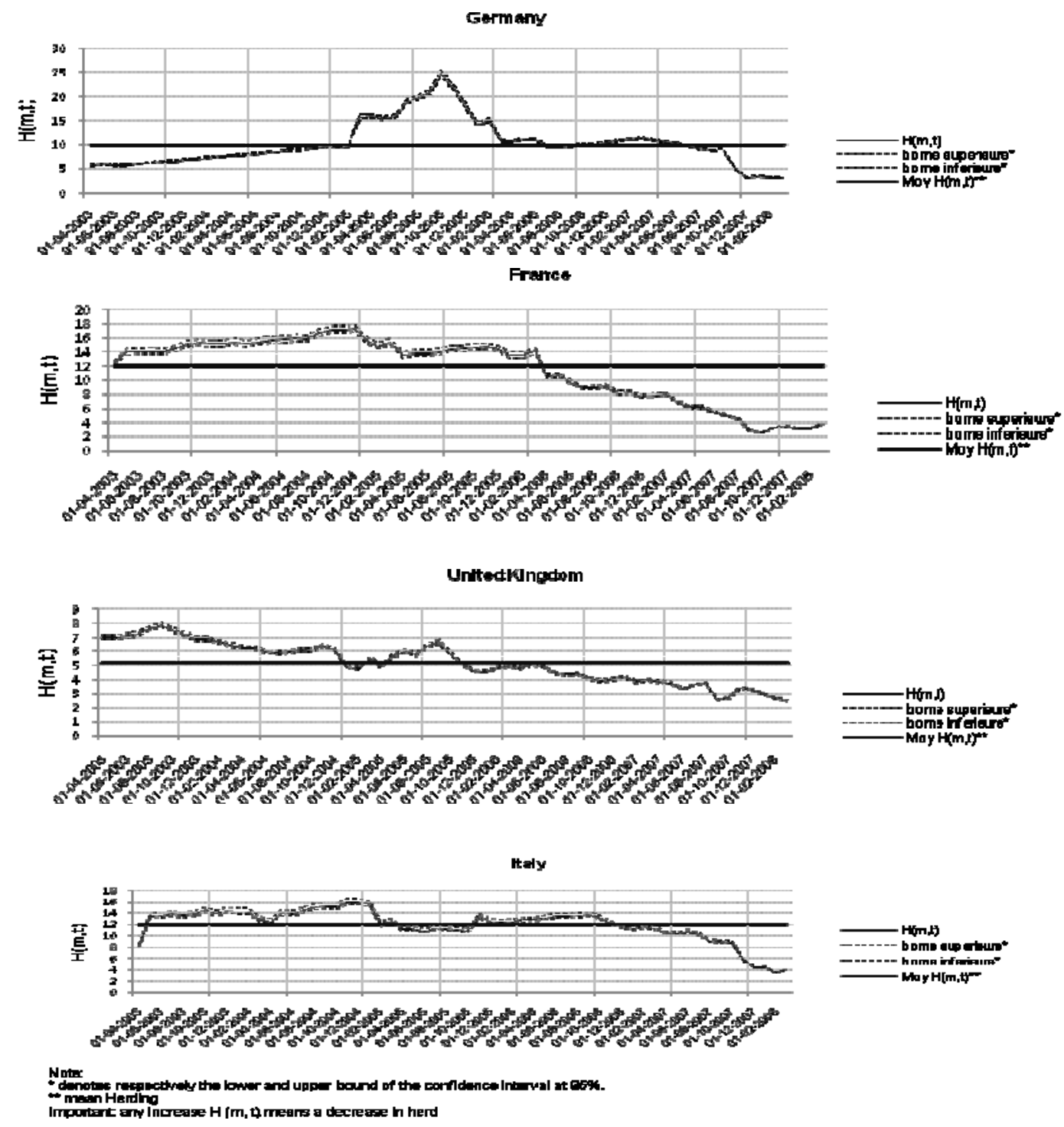

Figure 1. Herd behaviour Measurement in market Performance 


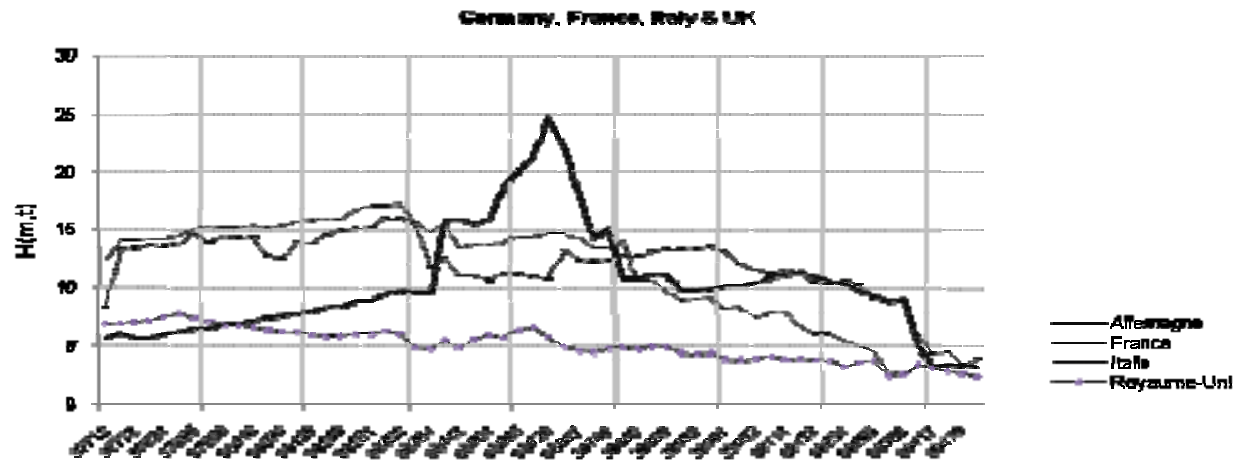

Figure 2. Measure of Herd Behaviour around the performance of the market for the complete sample
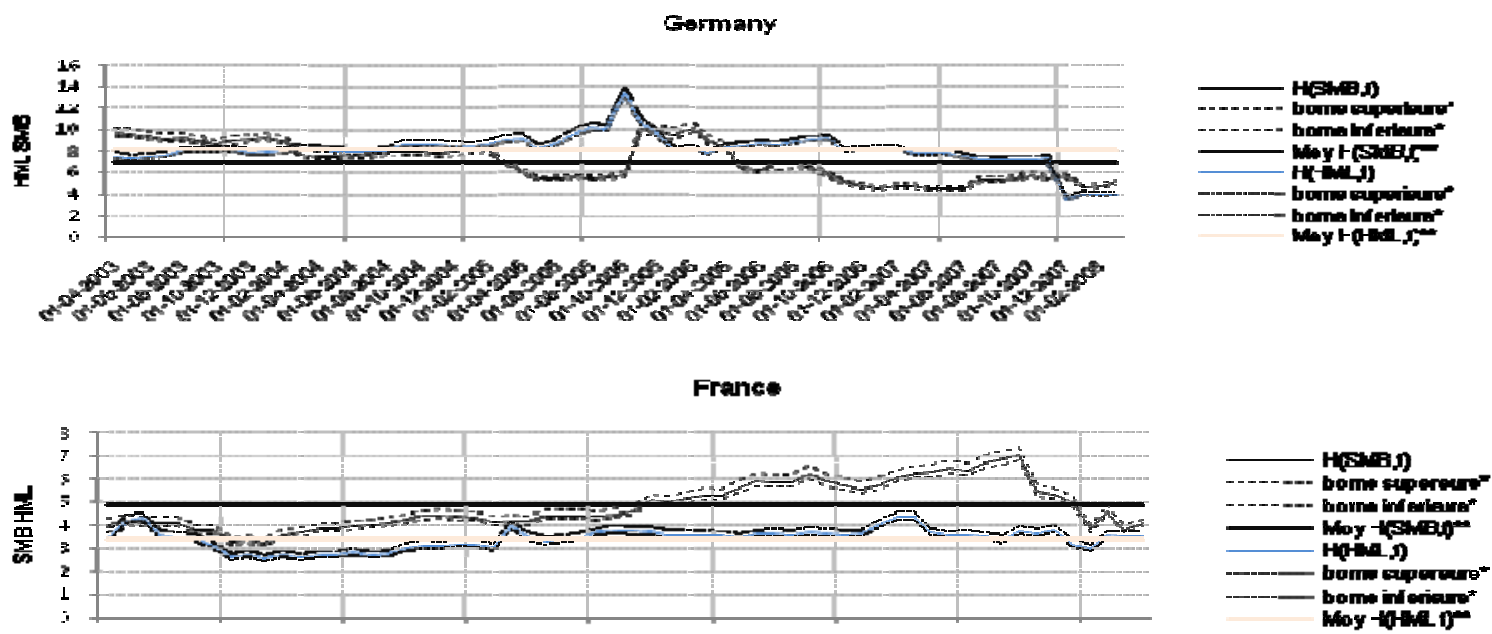

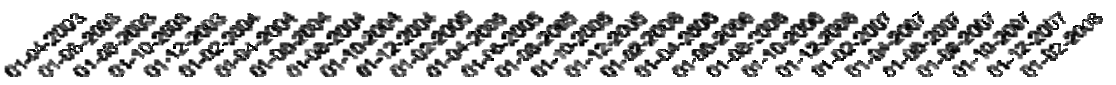
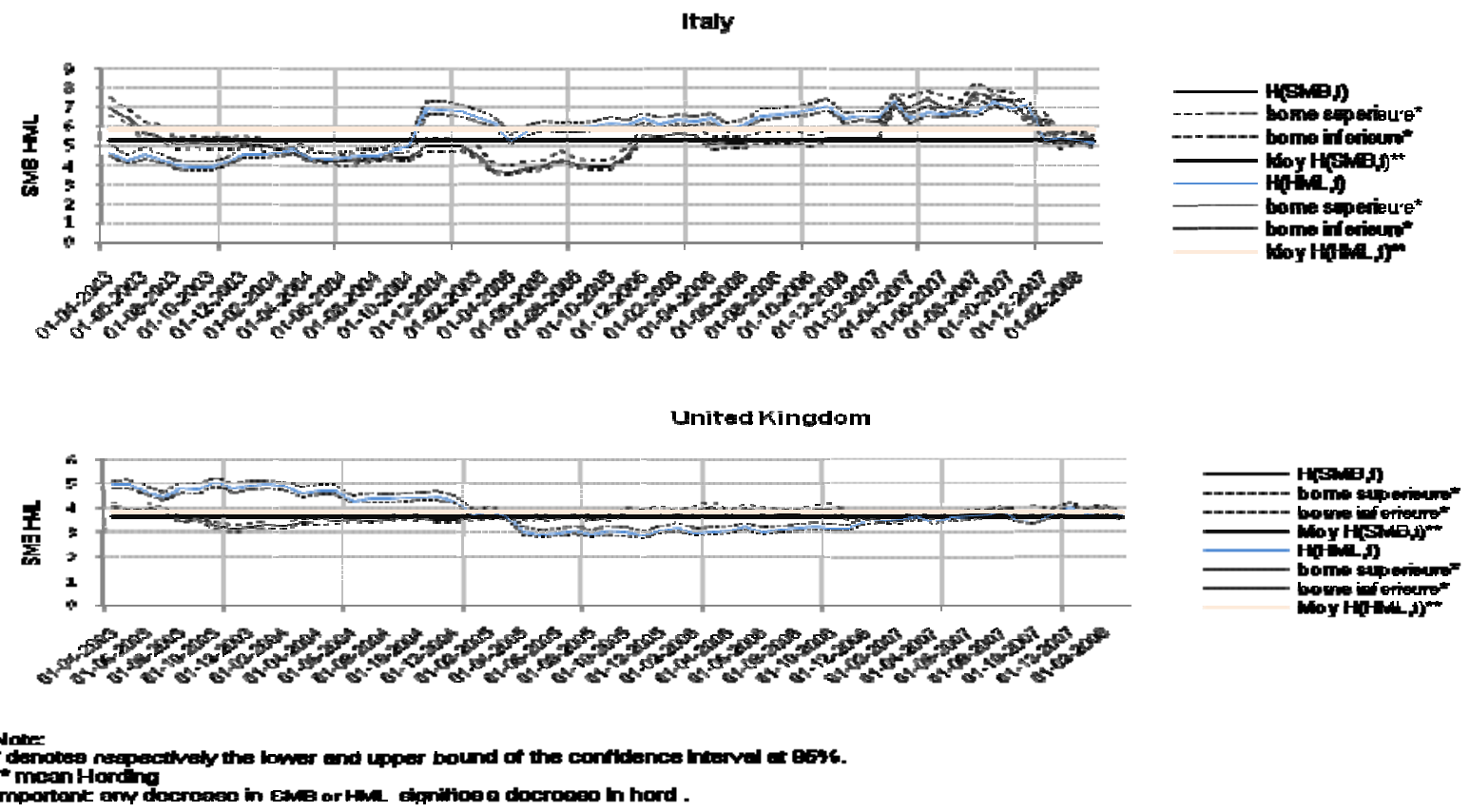

Figure 3. Herding Behaviour around the factors of $S M B \& H M L$ 


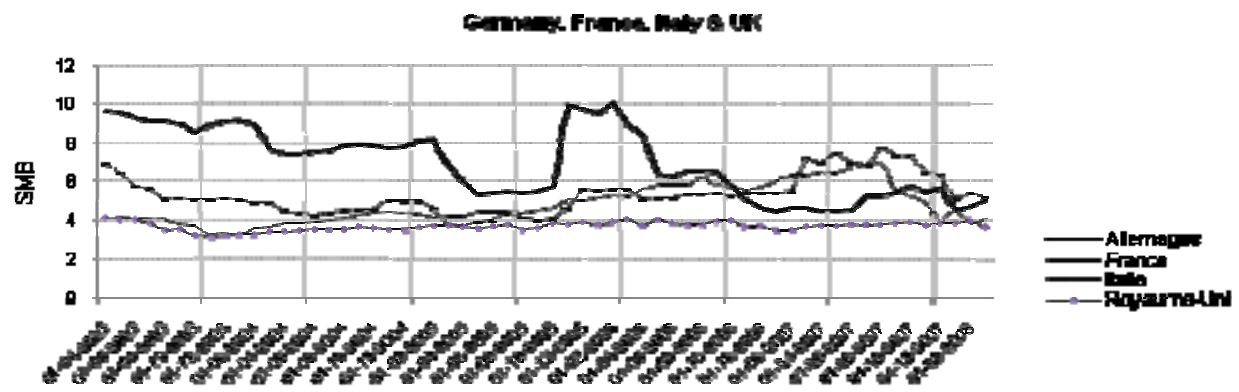

Figure 4. Comparison of the measurement of the Herding around factor $S M B$ for the whole of the countries

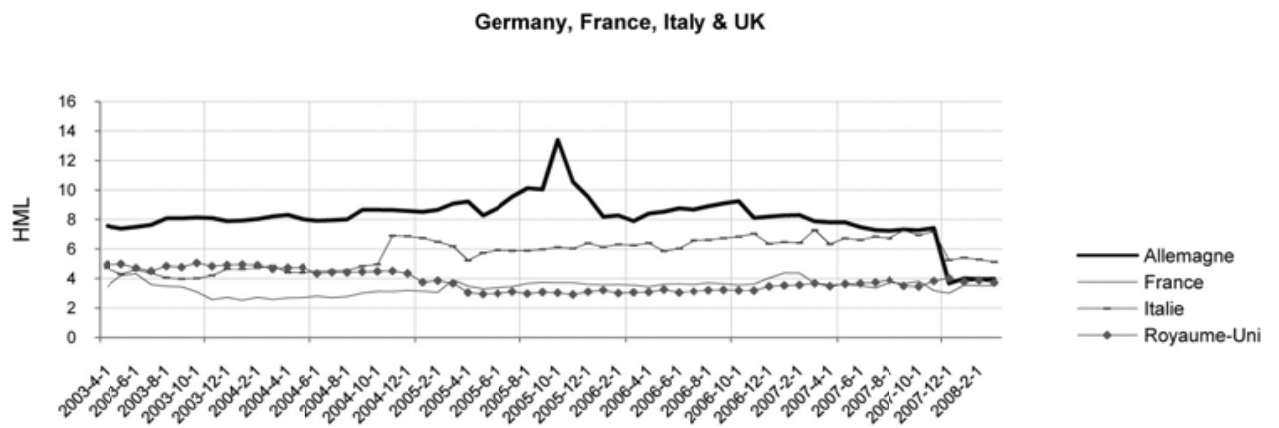

Figure 5. Comparison of the measurement of the Herding around factor HML for all countries

Annexe 1. The different styles of Management

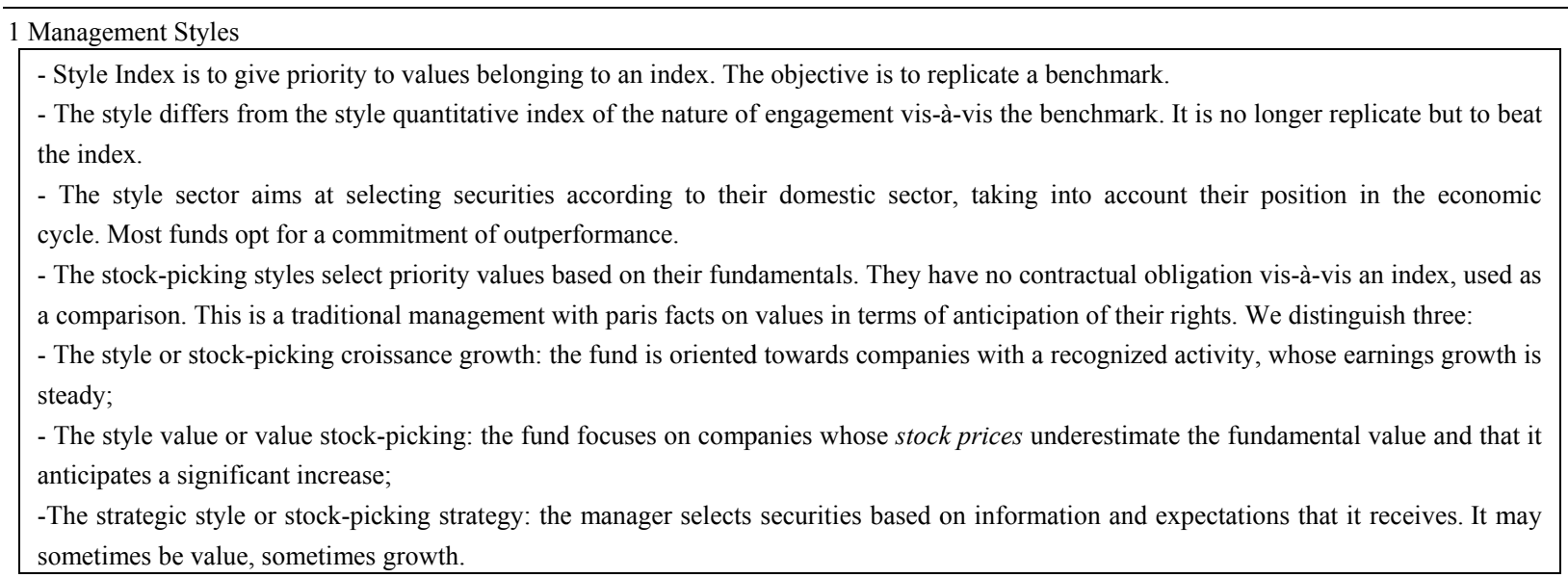

Source 1 (AAron, et al. 2005), page 3. 
Annexe 2. Herding around the factors of $S M B$ and $H M L$
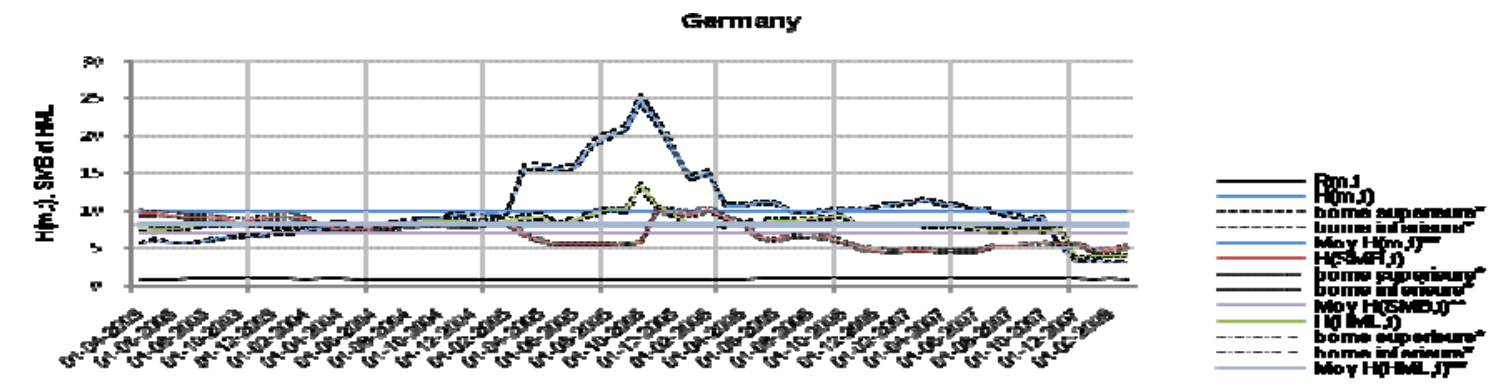

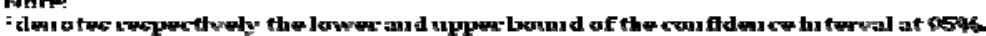

: : Average Heavilhy.

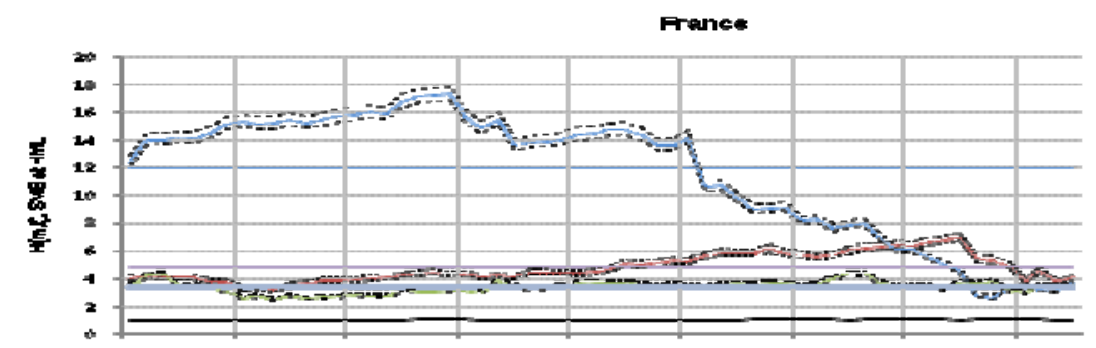

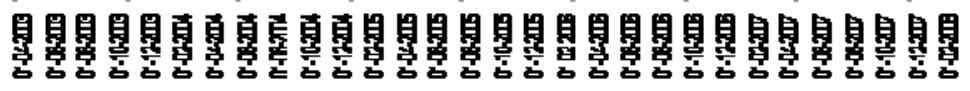

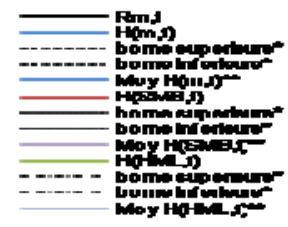

mari

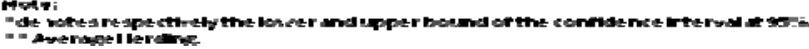

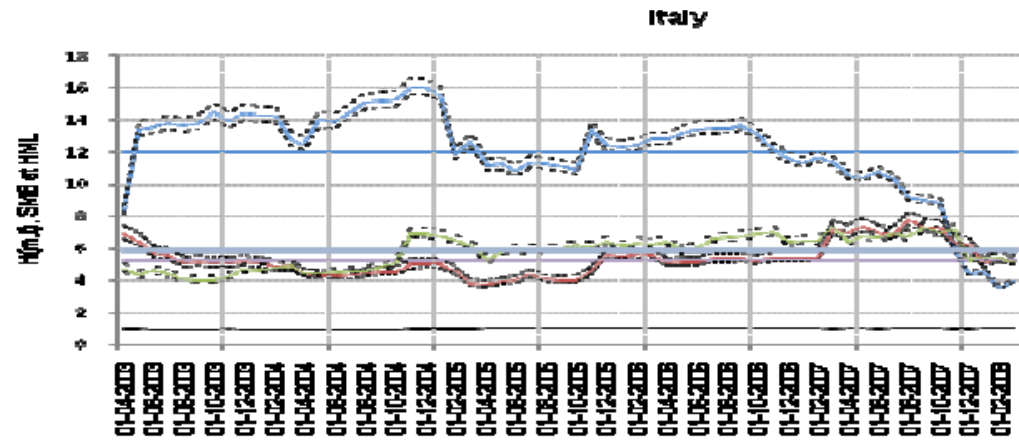

Note:

clento tes respectively the lower snd upper bound of the confidence intersd at $95 \%$.

- Aver Herdine

United KIngtom

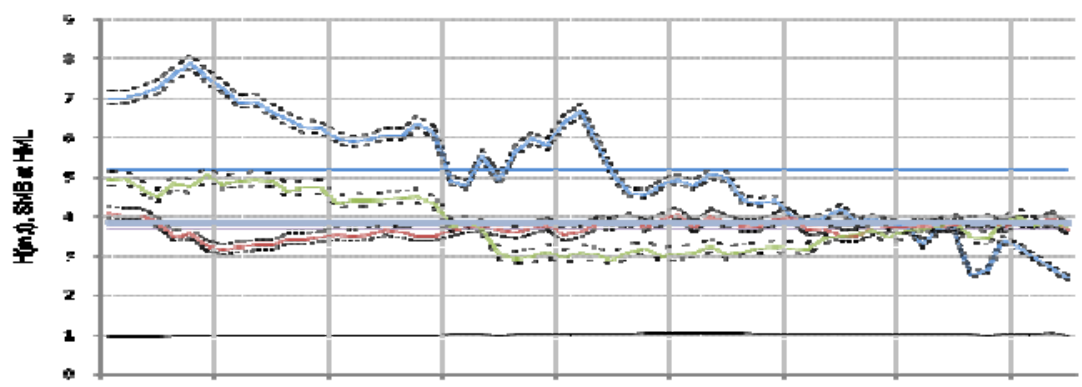

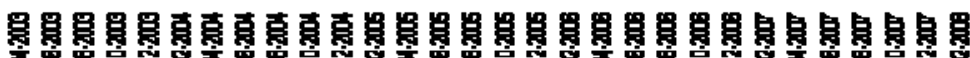

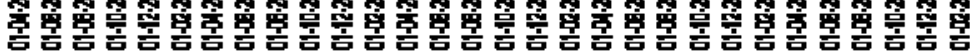
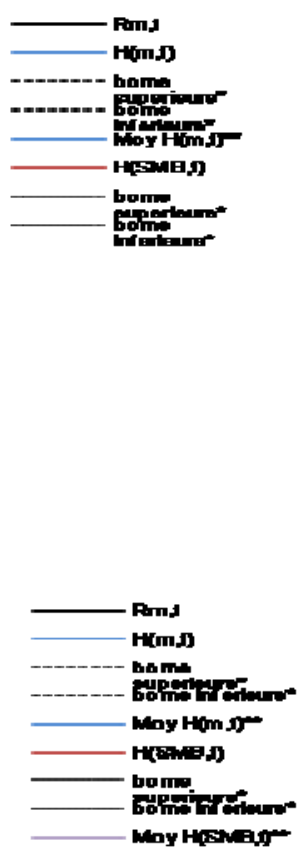

Hot?:

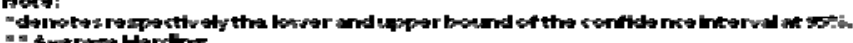

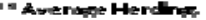

